\title{
Influence of supplemented coated-cysteamine on morphology, apoptosis and oxidative stress status of gastrointestinal tract
}



\begin{abstract}
Background: Cysteamine was coated to cover its odor and maintain the stability. However, coated cysteamine (CC) has not been clearly evaluated for its effects on the gastrointestinal mucosa status. We hypothesize that the appropriate CC supplementation in diet impacts the stomach and intestinal mucosa variously through regulating the morphology, apoptosis, and oxidative stress status in model of pigs.

Results: The results showed that villus height increased $(P<0.05)$, and crypt depth decreased $(P<0.05)$ in the ileum when pigs were fed the diet with low cysteamine (LCS) compared with the control diet. The ileal lesion score in the LCS group was significantly $(P<0.01)$ lower than that in the control group, while the gastric lesion score in the CC group was significantly $(P<0.01)$ higher compared with that of the control group. It also showed that the activities of total superoxide dismutase (T-SOD) and diamine oxidase (DAO) were upregulated $(P<0.05)$ in the LCS group. In addition, Bax and caspase 3 immunore-activity increased $(P<0.01)$, and Bcl-2 immunoreactivity decreased $(P<0.01)$ in the gastric mucosa of pigs fed the diet with high cysteamine (HCS). The Bax and caspase 3 immunoreactivity decreased $(P<0.01)$, and $\mathrm{BCl}-2$ immunoreactivity increased $(P<0.01)$ in ileum mucosa of pigs fed the HCS diet.
\end{abstract}

Conclusions: Although moderate dietary coated cysteamine showed positive effects on Gl mucosal morphology, apoptosis, and oxidative stress status, the excess coated cysteamine may cause apoptosis leading to Gl damage in pigs.

Keywords: Cysteamine, Coating technology, Gastrointestinal tract, Pigs

\section{Background}

Cysteamine is used in oral therapy to treat cystinosis, which is an autosomal recessive lysosomal storage disease caused by mutations in the CTNS, which is the gene encoding the protein cystinosin in human [1]. Being depredated from cysteine, cysteamine is the simplest stable aminothiol. It is used as the hydrochloride salt, because it is readily oxidized to the disulphides in the presence of air. Cysteamine also improves growth of children with cystinosis [2, 3]. As a feed additive, it shows stable improvement in protein digestion and meat colour in

\footnotetext{
* Correspondence: liuhn@isa.ac.cn; yinyulong@isa.ac.cn

${ }^{+}$Hongnan Liu and Miaomiao Bai contributed equally to this work.

'Scientific Observing and Experimental Station of Animal Nutrition and Feed

Science in South-Central, Ministry of Agriculture, Hunan Provincial

Engineering Research Center for Healthy Breeding of Livestock and Poultry,

Key Laboratory of Agro-ecological Processes in Subtropical Region, Institute

of Subtropical Agriculture, Chinese Academy of Sciences, 644 Yuanda 2

Road, Changsha 410125, China

Full list of author information is available at the end of the article
}

finishing pigs [4-6]. It decreases protein breakdown, regulates hormone secretion, and reduces back fat.

Oral formulations of cysteamine may cause adverse effects, including the reduction of motor activity and generalized haemorrhage in the gastrointestinal tract and kidneys. An oral dose of $660 \mathrm{mg} \mathrm{kg}^{-1}$ cysteamine bitartrate was fatal to rats. We found a low dose of dietary inclusion of cysteamine (at $30 \mathrm{mg} \mathrm{kg}^{-1}$ ) improved growth performance and carcass quality [4]. However, the stomach fluid $\mathrm{pH}$ value was decreased to 2.8 (at $50 \mathrm{mg} \mathrm{kg}^{-1}$ ) from 3.8 without cysteamine supplement. Oral cysteamine results in increasing gastrin and gastric acid production in laboratory animals [7-9]. Children with cystinosis and oral cysteamine administration were found to have a three-fold increase in gastric acid production and a $50 \%$ rise in serum gastrin levels above baseline $[10,11]$. Thus, gastrointestinal (GI) symptoms are common in the animal receiving long term oral cysteamine. On this account, cysteamine is used to induce intestinal ulceration in an 
animal model. In addition to mucosal injury, a high dose $(>300 \mathrm{mg} / \mathrm{kg}$ ) in a single subcutaneous injection may induce hypotension and neurological symptoms [12].

An enteric coating is a useful strategy for the oral medication or feed additive that prevents its dissolution or disintegration in the acidic environment of the stomach [13]. Ten years ago, the enteric coated cysteamine was firstly reported to reduce daily administration for patients with cystinosis [14]. However, the effect of enteric coated cysteamine on the gastrointestinal mucosa and the optimum additive range has not been systematically evaluated. Therefore, the current study aims to quantify the adverse effects of dietary $\mathrm{CC}$ on morphology, apoptosis, and oxidative stress status of the gastrointestinal tract in the animal model of young pigs. The results of this study may further elucidate the role of the gut on the systemic bioavailability of dietary coated cysteamine in young pigs.

\section{Results}

\section{Mucosal MDA, T-SOD, T-AOC and DAO activity}

The LCS diet elevated the activity of ileum mucosal TSOD compared to that of the control group $(P<0.05)$ (Fig. 1b). No significant difference was found in T-SOD activity between the HCS and control group. The activity of ileum mucosal DAO was also increased in the LCS group, but not that of HCS $(P<0.05)$, in comparison with that of the control group (Fig. 1d). However, dietary coated cysteamine showed no effects on mucosal $\mathrm{T}-\mathrm{AOC}$ and MDA concentrations among the groups.

\section{GI morphology and lesions}

GI morphology in ileal was determined to evaluate the effects caused by dietary cysteamine (Table 1). Supplementation of low coated cysteamine increased ileal villus height and reduced the crypt depth $(P<0.05)$. Dietary high coated cysteamine also reduced the ileal crypt $(P<0.05)$. Villus height:crypt $(\mathrm{V} / \mathrm{C})$ ratio was increased by LCS diet compared to that of the control diet $(P<0.05)$.

To explore the effects of coated cysteamine on pigs' intestinal membrane barrier, we observed intestine pathologic sections and determined the intestinal mucous damage score (Table 1). The HCS group had a higher ileal lesion score compared to the control group $(P<0.05)$, whereas LCS had lower one $(P<0.05)$. In the stomach, the lesion score was increased in the HCS group $(P<0.05)$. No histological damage was found in the GI tissue of the control pigs (Fig. 2). Cell counting on the intestine pathologic section showed no effects on the amounts of intraepithelial lymphocytes, mucosal mast cells, and peyer patches induced by dietary coated cysteamine. The number of submucosal mast cells was significantly increased by the HCS diet $(P<0.05)$.


Fig. 1 lleum mucosal MDA (a), T-SOD (b), T-AOC (c) and DAO (d) activity. CON = pigs in the negative control group were fed a basal diet; LCS and $\mathrm{HCS}=$ pigs in coated cysteamine group were fed a basal diet supplemented with 35 and $280 \mathrm{mg} / \mathrm{kg}$ of cysteamine. ${ }^{*}$ presents significant changes compared with CON group. Values are mean \pm SEM, $n=8$ 
Table 1 Effects of dietary supplementation with coated cysteamine on Gl morphology and mucous damage score of finishing pigs ${ }^{a}$

\begin{tabular}{|c|c|c|c|c|c|}
\hline Index & CON & LCS & HCS & SEM & $P$-value \\
\hline Villus height, $\mu \mathrm{m}$ & $504.1^{\mathrm{a}}$ & $559.1^{\mathrm{b}}$ & $522.9^{\mathrm{ab}}$ & 14.71 & 0.038 \\
\hline Crypt depth, $\mu \mathrm{m}$ & $162.7^{\mathrm{a}}$ & $147.5^{\mathrm{b}}$ & $143.3^{b}$ & 5.058 & 0.025 \\
\hline Villus height:crypt depth, $\mu \mathrm{m}: \mu \mathrm{m}$ & $3.15^{\mathrm{a}}$ & $3.91^{\mathrm{b}}$ & $3.72^{\mathrm{ab}}$ & 0.153 & 0.003 \\
\hline Ileal lesion score & $1.94^{\mathrm{a}}$ & $1.00^{\mathrm{b}}$ & $2.06^{\mathrm{a}}$ & 0.179 & $<0.001$ \\
\hline Gastric Lesion score & $1.313^{\mathrm{a}}$ & $1.450^{\mathrm{a}}$ & $2.125^{\mathrm{b}}$ & 0.174 & 0.008 \\
\hline Goblet cells /100 enterocytes & 10.30 & 8.900 & 8.950 & 0.541 & 0.126 \\
\hline Intraepithelial lymphocytes /100 enterocytes & 34.65 & 36.25 & 36.25 & 0.702 & 0.199 \\
\hline Mucosal mast cell ${ }^{\mathrm{b}}$ & 2.75 & 2.95 & 2.45 & 0.512 & 0.788 \\
\hline Submucosal mast cell ${ }^{\mathrm{b}}$ & $8.10^{\mathrm{a}}$ & $8.55^{\mathrm{a}}$ & $6.50^{b}$ & 0.386 & 0.001 \\
\hline Peyer patch ${ }^{c}$ & 1.625 & 0.625 & 0.125 & 0.435 & 0.141 \\
\hline
\end{tabular}

${ }^{a}$ Eight piglets per treatment. CON = pigs in the negative control group were fed a basal diet; LCS and HCS = pigs in coated cysteamine group were fed a basal diet supplemented with 35 and $280 \mathrm{mg} / \mathrm{kg}$ of cysteamine

${ }^{b}$ All of the cells were counted in $41,023 \mu \mathrm{m}^{\wedge 2}$ area by microscope

${ }^{\mathrm{C}} \mathrm{All}$ of the cells were counted under $40 \times 10$ by microscope

\section{Apoptotic marker expression by ileum compartment} Apoptotic marker expression in the ileal tissue showed that bax immunoreactivity in the ileum basilar villus was reduced in the LCS group and increased in the HCS group compared to that of the control group $(P<0.05$, Table 2). Caspase 3 immunoreactivity was increased $(P<0.05)$, and bcl-2 immunoreactivity was decreased $(P<0.05)$ in both the apical and basilar villus of pigs fed the HCS diet, whereas, the LCS diet reduced Caspase 3 immunoreactivity and elevated the bcl-2 immunoreactivity $(P<0.05)$. Immunohistochemical $(\mathrm{IHC})$ staining to identify cells expressing anti-apoptotic bcl-2, pro-apoptotic caspase 3, and bax proteins in the gastric and ileum mucosa showed similar trends (Figs. 3 and 4).

\section{Mucosal protein, DNA and RNA contents in lleal mucous}

In comparison with the control group, dietary supplementation of coated cysteamine had no effects on DNA




Table 2 Apoptotic marker expression by intestinal compartment ${ }^{\mathrm{a}}$

\begin{tabular}{lll}
\hline Marker, by group & lleum apical villus & lleum basilar villus \\
\hline Bax & & \\
CON & $11,349 \pm 897^{\mathrm{ab}}$ & $2276 \pm 211^{\mathrm{a}}$ \\
LCS & $8603 \pm 727^{\mathrm{a}}$ & $1522 \pm 157^{\mathrm{b}}$ \\
HCS & $14,982 \pm 1029^{\mathrm{b}}$ & $4372 \pm 348^{\mathrm{c}}$ \\
BCl-2 & \\
CON & $8539 \pm 1042^{\mathrm{a}}$ & $2520 \pm 253^{\mathrm{a}}$ \\
LCS & $11,653 \pm 1532^{\mathrm{a}}$ & $4035 \pm 525^{\mathrm{b}}$ \\
HCS & $5186 \pm 707^{\mathrm{b}}$ & $1243 \pm 142^{\mathrm{c}}$ \\
Caspase 3 & \\
CON & $7373 \pm 619^{\mathrm{a}}$ & $3037 \pm 326^{\mathrm{a}}$ \\
LCS & $4152 \pm 409^{\mathrm{b}}$ & $2334 \pm 202^{\mathrm{b}}$ \\
HCS & $11,328 \pm 1066^{\mathrm{c}}$ & $4845 \pm 480^{\mathrm{c}}$ \\
\hline
\end{tabular}

${ }^{a}$ Eight piglets per treatment. $\mathrm{CON}$ = pigs in the negative control group were fed a basal diet; LCS and HCS = pigs in coated cysteamine group were fed a basal diet supplemented with 35 and $280 \mathrm{mg} / \mathrm{kg}$ of cysteamine concentrations, or the RNA/DNA or protein/DNA ratios in the ileum (Table 3).

\section{Discussion}

Cysteamine is formed by the decarboxylation of cysteine and the component of Coenzyme A. It is endogenously synthesized, metabolized and excreted rapidly by the animal organism [15]. Its use was approved as a dietary supplement by the FDA in 2004. In animal husbandry, cysteamine is used as a feed additive in recent years. EMEA (The European Agency for the Evaluation of Medicinal Products) summarized the oral $\mathrm{LD}_{50}$ value of cysteamine hydrochloride in mice is $625 \mathrm{mg} / \mathrm{kg} \sim 1352$ $\mathrm{mg} / \mathrm{kg}$ [16]. In vivo, it is quickly absorbed from the intestinal tract, and metabolized to cystamine, cysteine, glutathione and taurine. The reactivity of the compound is due to the $\mathrm{SH}$ and the $\mathrm{NH} 2$ group in the molecule. Because of its ability to produce somatostatin in the rat stomach,
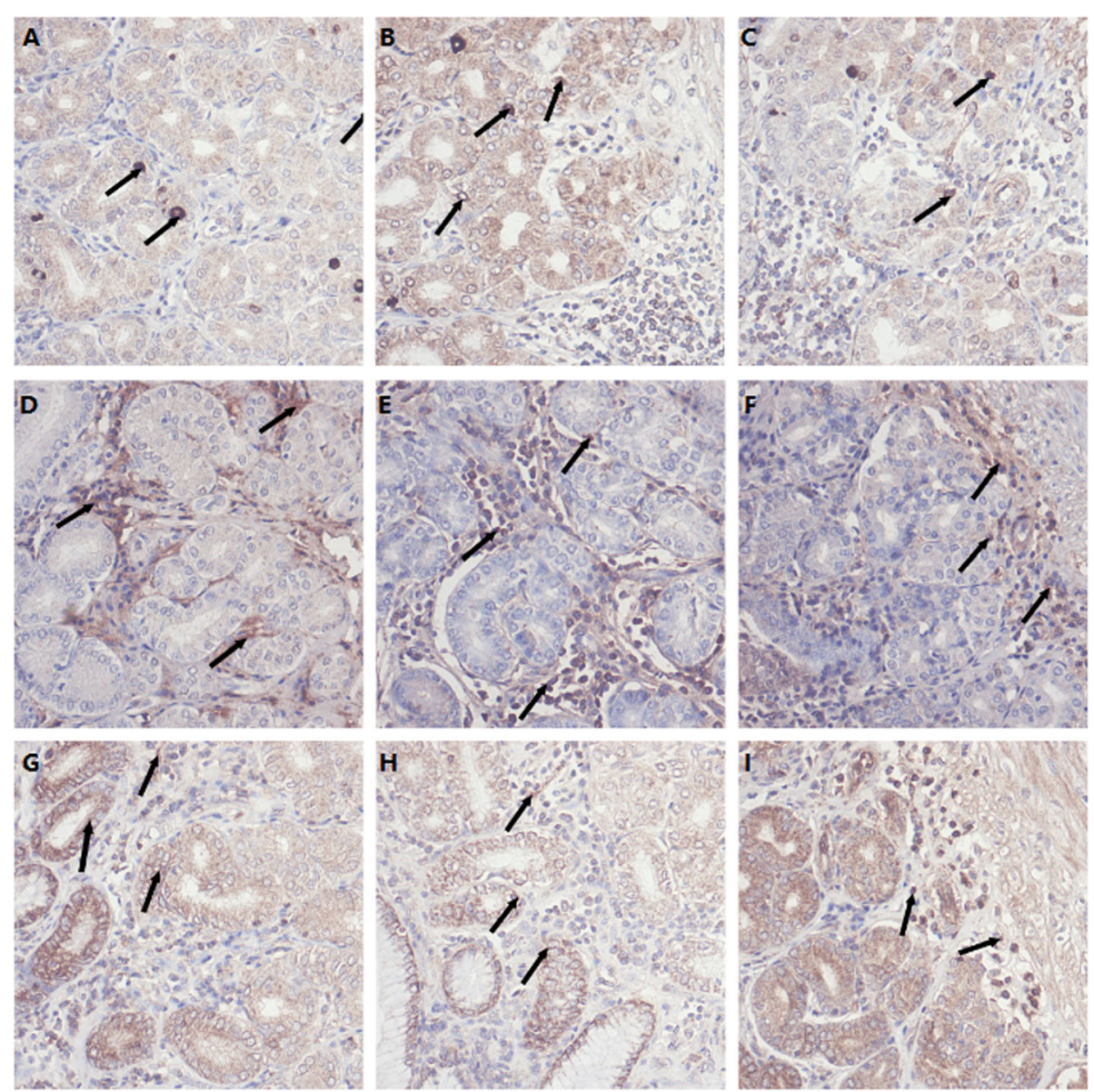

Fig. 3 Immunohistochemical (IHC) staining identifying cells expressing anti-apoptotic BCl-2 (a-c) and the pro-apoptotic Casp3 (d-f) and Bax (g-i) proteins in gastric mucosa. Positive cells are stained red-brown. Gastric mucosa of pig fed CON diet (a), gastric mucosa of pig fed LCS diet (b) and gastric mucosa of pig fed HCS diet (c) showing BCl-2 cells; gastric mucosa of pig fed CON diet (d), gastric mucosa of pig fed LCS diet (e) and gastric mucosa of pig fed HCS diet (f) showing Casp3 cells; gastric mucosa of pig fed CON diet (g), gastric mucosa of pig fed LCS diet (H) and gastric mucosa of pig fed HCS diet (i) showing Bax cells. Arrows presented the positive protein in the mucosa 

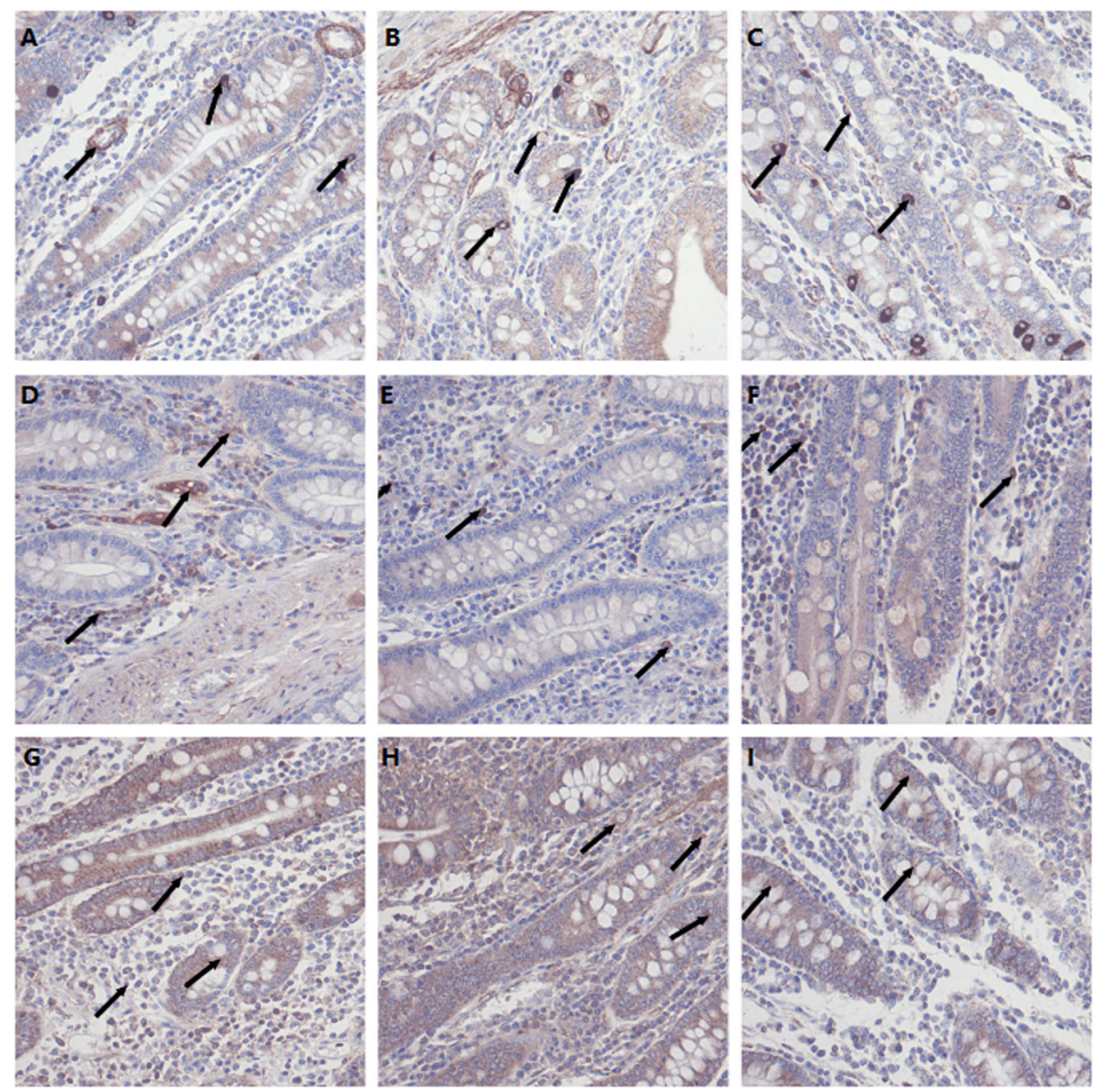

Fig. 4 Immunohistochemical (IHC) staining identifying cells expressing anti-apoptotic Bcl-2 (a-c) and the pro-apoptotic Casp3 (d-f) and Bax (g-i) proteins in ilium mucosa. Positive cells are stained red-brown. Ilium mucosa mucosa of pig fed CON diet (a), ilium mucosa mucosa of pig fed LCS diet (b) and ilium mucosa of pig fed HCS diet (c) showing BCl-2 cells; ilium mucosa of pig fed CON diet (d), ilium mucosa of pig fed LCS diet (e) and ilium mucosa of pig fed HCS diet (f) showing Casp3 cells; ilium mucosa of pig fed CON diet (g), ilium mucosa of pig fed LCS diet (h) and ilium mucosa of pig fed HCS diet (i) showing Bax cells. Arrows presented the positive protein in the mucosa

cysteamine has been used as a drug for the establishment of animal models of acute intestinal ulcers [17]. Plus, the characteristics such as deliquescence and pungent odors smell has to be modified by coating. However, differences in the control of the coating process and quality made the differences on the effects of supplemented coated cysteamines on the gastrointestinal mucosa.

The villi of intestine gradually became lower eventually forming a villous surface by subcutaneous or oral

Table 3 Effects of coated cysteamine supplementation on jejunum mucosal protein, DNA and RNA contents of finishing pigs ${ }^{a}$

\begin{tabular}{llllll}
\hline Index & CON & LCS & HCS & SEM & $P$-value \\
\hline Protein, mg/g tissue & 3.381 & 3.282 & 3.104 & 0.2300 & 0.8934 \\
RNA/DNA & 1.978 & 1.904 & 0.7852 & 0.3615 & 0.3015 \\
Protein/DNA, mg/ug & 0.0122 & 0.0072 & 0.0046 & 0.0017 & 0.1424
\end{tabular}

${ }^{a}$ Eight piglets per treatment. $\mathrm{CON}=$ pigs in the negative control group were fed a basal diet; LCS and HCS = pigs in coated cysteamine group were fed a basal diet supplemented with 35 and $280 \mathrm{mg} / \mathrm{kg}$ of cysteamine administration of cysteamine at $280 \mathrm{mg} \cdot \mathrm{kg}^{-1} \mathrm{BW}$ [18]. Cysteamine $\left(100 \mathrm{mg} \cdot \mathrm{kg}^{-1} \mathrm{bw}\right)$ induced duodenal epithelial cell damage, marked exfoliation from the villous tip, was also observed at $1 \mathrm{~h}$ in rats after administration [19]. In this experiment, supplemented coated cysteamine at 35 $\mathrm{mg} \bullet \mathrm{kg}^{-1}$ improved the villus height and V:C, decreased crypt depth. It is consisted with the previous report, which showed cysteamine improved intestinal integrity [20]. Crypt lengthening is accompanied by intestinal damage when assessed histologically. HCS also improved intestinal morphology by decreasing the crypt depth, which could be attributed to the protection by coating technique in present study. However, coating technology is incapable to inhibit the damage of the intestinal mucosa by high levels CC. The ileal lesion was proportional to the level of dietary cysteamine, which may be due to the thorough release of cysteamine at the ileum.

After shorten the villi, defects in the epithelium, necrosis, inflammation of the lamina propria, and a 
localized ulcer developed in the gastric ulcer model administrated by cysteamine [18]. GI Lesions is the indictor to monitor the GI damage. The damage in intestine and stomach was attributed to the secretion of gastric acid promoted by cysteamine [7]. In present study, supplement coated cysteamine induced gastric damage even at $35 \mathrm{mg} \cdot \mathrm{kg}^{-1}$ in diet. The reducing lesion score in LCS indicated the protection of cysteamine in intestine but not stomach. We found supplement cysteamine at $50 \mathrm{mg} \cdot \mathrm{kg}^{-1}$ in diet damage the gastric mucosa with minor parakeratosis in the stomach in 2005 [21]. In many cases, cysteamine may have opposite effects on the same parameters, depend on the supplementation dose. Cysteamine acts as a gastric ucerogenic at dose of 100 to $300 \mathrm{mg} \cdot \mathrm{kg}^{-1}$, but also protects against ulcerogenic effects of other compound [16]. Although Intelligent Microcapsule Technology (IMT) was used to protect intestinal damage from cysteamine, the high level cysteamine in diet elevated the gastric lesion score, indicating the lower dose could be more suitable level of coated supplementation for pigs.

Activated caspases causes the changes in mitochondrial permeability and eventually led to apoptosis. Bcl-2 inhibited the activation of caspases in mitochondria and inhibited cell apoptosis. Bax is a cell apoptosis-promoting gene belonging to bcl-2 family. The overexpression of bax antagonizes the protection of bcl-2 and lead to apoptosis. Bcl-2 also has effects on antixidation in animals. The apoptotic marker expression results indicated that as an endogenous compound, proper level of supplemented cysteamine may protect villus from apoptosis in the ileum, whereas dietary cysteamine may cause disturbance of physiological processes at abnormally high concentrations.

Coated cysteamine supplemented in pig diet could improve antioxidant status and delay meat discoloration by improving glutathione levels and antioxidase activity [22]. In mice, it showed protection against radioactivity in skin, vessels and the brain parenchyma (at around intraperitoneal doses of $250 \mathrm{mg} \cdot \mathrm{kg}^{-1} \mathrm{bw}$ ) [23]. The mechanism for the protection was by the antioxidant synthesis such as glutathione [24]. In this study, T-SOD and DAO activity but not glutathione (data not showed), were elevated by supplement coated cysteamine at level of $35 \mathrm{mg} \cdot \mathrm{kg}^{-1}$ diet, which is not in conformity with the previous reports. In rats, injected cysteamine inhibited DAO activity on two successive days at the dose of more than $400 \mathrm{mg} \cdot \mathrm{kg}^{-1} \mathrm{bw}$, indicating that high cysteamine induced ulceration, which reduced the enzyme activity [25]. In vitro, cysteamine administration increased manganese superoxide dismutase (MnSOD) activity in cultured astroglia and protected these cells from subsequent $\mathrm{H}_{2} \mathrm{O}_{2}$ and mechanoenzymatic stress [26]. In addition, cysteamine was about 5 times as active (in terms of increased $\mathrm{O}_{2}$ consumption at $\mathrm{pH} 7.5$ ) as the previously reported peroxidase-oxidase substrates
$\mathrm{NADPH}$, dihydroxyfumaric acid and indol-3-ylacetic acid in vitro [27]. The disparity in results may be explained by the differences in the animal organ, intake approach (including coated or not), dose and duration.

\section{Conclusion}

Taking together, supplemented coated cysteamine at 35 $\mathrm{mg} \cdot \mathrm{kg}^{-1}$ diet improved the ileum mucous healthy through regulating the oxidation status and expression of apoptosisrelated proteins in pigs. Although IMT helped cysteamine to promote the intestine morphology such as reducing crypt depth, excess supplemented coated cysteamine in diet may cause damage on gastrointestinal mucous.

\section{Methods}

Animals, experimental design, and diets

The experimental protocol was approved by the Animal Welfare Committee of the Institute of Subtropical Agriculture, The Chinese Academy of Sciences. A total of 216 crossbred finishing pigs (Duroc $\times$ Landrace $\times$ Yorkshire) with an initial BW of $88.3 \pm 0.3 \mathrm{~kg}$ provided by a commercial farm (Jiahe biotechnology co. LTD, Hunan, Changsha, China) was randomly assigned into 3 dietary groups, fed a corn-soybean powder diet containing 0 (control), 35 (LCS), and 280 (HCS) $\mathrm{mg} \cdot \mathrm{kg}^{-1}$ of cysteamine supplied as coated-cysteamine hydrochloride in diet for 29 days. The control diet met the nutrient requirements for finishing pigs recommended by the National Research Council (2012) and feed intakes were not affected by treatments [22]. In each group, pigs were housed in 8 pens (replicate) with 9 pigs/pen. The experiment was performed in a commercial farm (New Hope Liuhe Limited Liability Company, Yishui, China). All the animals had free access to feeds and drinking water. The basal diet met or exceeded nutrient requirements for pigs recommended by the NRC (2012) in the previous study [22]. Coated cysteamine hydrochloride, supplied by Hangzhou King Techina Technology Co., Ltd. (Hangzhou, China), contained 27\% cysteamine hydrochloride. At the end of the experiment, one pig was randomly selected from each pen. The person who selected the pigs was blinded to all of the groups the pigs belonged in. Other animals were left to the farm. The selected pigs were killed by exsanguination after electrical stunning in the morning. After exsanguination, the stomach and small intestinal sample was collected. Approximately $20 \mathrm{~cm}$ of tissue was removed from the centre of the jejunum and ileum section [28]. Approximately $5 \mathrm{~g}$ intestinal tissue were flushed with ice-cold saline to recover mucosa. The mucosa samples were snap-frozen in liquid nitrogen and stored at $-80^{\circ} \mathrm{C}$. Extra intestinal samples $(2$ $\mathrm{cm})$ and stomach $(2 \mathrm{~g})$ samples were rinsed with precooling saline and fixed in formaldehyde solution for histological measurements [29]. 
Analysis of intestinal mucosal protein, DNA and RNA contents Protein content of intestinal mucosal supernatant was analyzed by the method of Lowry et al. [30]. Mucosal DNA content was measured by a fluorometric assay [31]. RNA was determined by spectrophotometry by a modified Schmidt-Tannhauser method [32].

\section{Mucosal MDA, T-SOD, T-AOC and DAO activity}

Mucosal activities of Malondialdehyde (MDA), Superoxide Dismutase (SOD), and total antioxidative capacity (T-AOC) were measured using spectrophotometric kits in accordance with the manufacturer's instructions (Nanjing Jiangcheng Biotechnology Institute, China). Diamine oxidase (DAO) was measured according to a previous report $[33,34]$.

\section{Evaluation of gastric and ileal mucosal lesions}

To estimate the severity of gastric and ileal erosions induced by $\mathrm{CC}$, gastric, and intestinal damage was scored macroscopically on a scale of $0-3$ based on the severity of hyperaemia and haemorrhagic erosions as previously described: 0 , almost normal mucosa; 1 , mildhyperemia; 2 , moderate hyperaemia and several erosions; and 3, severe hyperaemia and multiple erosions. Scoring was conducted by a person blind to treatment assignment [35].

\section{Determination of gastric and lleal morphology}

Haematoxylin and eosin (H \& E) histological staining was performed on parallel sections of ileal tissue. Ileal tissue was immersed in $4 \%$ paraformaldehyde for $4 \mathrm{~h}$ and transferred to $70 \%$ ethanol. Individual lobes of ileal tissue biopsy material were placed in processing cassettes, dehydrated through a serial of alcohol gradient, and embedded in paraffin wax blocks. Ileal tissue was cut as $5 \mu \mathrm{m}$ sections and dewaxed in xylene, rehydrated through decreasing concentrations of ethanol, washed in PBS, and then stained with haematoxylin and eosin. After staining, sections were dehydrated through increasing concentrations of ethanol and xylene. All specimens were examined under a light microscope (Nikon, Japan). Villus height and crypt depth were measured using an image-analysis system [36].

\section{Detection of cells positive for bcl-2, bax, and caspase-3} protein in gastrointestinal tract by immunohistochemistry The immunohistochemical staining was performed as described by Wu et al. [37]. Bcl-2, Bax, and Caspase-3 protein were localized in the gastrointestinal tract by immunohistochemistry as previously described [38]. The antibodies used were Anti-Bax (BA0315), Anti-Bcl-2 (BA0412), Anti-Caspase-3 (BA0588), and goat anti-mouse IgG (ZSGB-BIO SP Kit).

The bcl-2, bax, and Caspase-3 positive cells were counted using a computer-supported imaging system connected to a light microscope (OlympusAX70) with an objective magnification of $\times 400$. Then, the Bcl-2, Bax, and Caspase- 3 protein expression were quantified by Image-Pro Plus 5.1 (USA) image analysis software. Each group was measured in five sections and each section was measured in five fields and averaged.

\section{Statistical analysis}

All data were expressed as means and analyzed statistically by the one-way ANOVA using SPSS 20 (SPSS Inc., Chicago, IL, USA). Each pig was considered an experimental unit. Duncan's multiple-range test was performed to identify differences between significant mean values. The differences were declared significant at $P<0.05$ and a trend at $0.05<P<0.10$ in all analyses, unless otherwise stated.

\section{Abbreviations}

bax: Bcl-2-associated X protein; bcl-2: B-cell lymphoma-2; caspase: cysteineaspartic proteases; CC: Coat cysteamine; DAO: Diamine oxidase; Gl: Gastrointestinal; IMT: Intelligent Microcapsule Technology; MDA: Malondialdehyde; MnSOD: Manganese superoxide dismutase; SOD: Superoxide Dismutase; T-AOC: Total antioxidative capacity

\section{Acknowledgements}

We thank Hangzhou King Techina Technology Company Academician Expert Workstation for providing technical assistance.

Ethical approval ethics approval and consent to participate The experimental protocol was approved by the Animal Welfare Committee of the Institute of Subtropical Agriculture, The Chinese Academy of Sciences. Explicit owner informed consent for inclusion of animals in this study was signed.

\section{Authors' contributions}

$\mathrm{HL}$ designed the study, and analyzed data, drafted the manuscript with MB. $\mathrm{MB}$ conducted the research. $\mathrm{KX}$, and $\mathrm{BT}$ participated in experimental design and statistical analysis. RY provided the methods to coat the cysteamine. $\mathrm{RH}$ and $Y Y$ participated in experimental design and helped draft the manuscript. Additionally, $\mathrm{HL}$ had final responsibility for content while all authors read and approved the final manuscript.

\section{Funding}

We would like to express sincere gratitude to the National Key Research and Development Program of China (2018YFD0501101) and Natural Science Foundation of Hunan Province of China (2018JJ3579). The research was also funded by the research program of Youth Talent Program of Hunan Province (2018RS3110), Youth Innovation Team Project of ISA, CAS (2017QNCXTD_TBE) and the China Agriculture Research System (CARS-35).

Availability of data and materials

The datasets generated and/or analysed during the current study are not publicly available to preserve the individual pigs' and their owners' privacy, but are available from the corresponding author on reasonable request.

Consent for publication

Prior to study enrolment, written owner consent was obtained for each pig.

\section{Competing interests}

The authors declare that they have no competing interests.

\section{Author details}

${ }^{1}$ Scientific Observing and Experimental Station of Animal Nutrition and Feed Science in South-Central, Ministry of Agriculture, Hunan Provincial Engineering Research Center for Healthy Breeding of Livestock and Poultry, Key Laboratory of Agro-ecological Processes in Subtropical Region, Institute 
of Subtropical Agriculture, Chinese Academy of Sciences, 644 Yuanda 2 Road, Changsha 410125, China. ${ }^{2}$ Hangzhou King Techina Technology Company Academician Expert Workstation, Hangzhou King Techina Technology Co., Ltd., Hangzhou 311107, China. ${ }^{3}$ Hunan Co-Innovation Center of Animal Production Safety, CICAPS, Changsha, Hunan 410128, People's Republic of China. ${ }^{4}$ College of Animal Science, South China Agricultural University, Guangzhou 510642, Guangdong, China.

Received: 21 June 2018 Accepted: 4 September 2019

Published online: 13 September 2019

\section{References}

1. Kleta R, Gahl WA. Pharmacological treatment of nephropathic cystinosis with cysteamine. Expert Opin Pharmacother. 2004;5(11):2255-62.

2. Wühl E, Haffner D, Offner G, Broyer M, van't Hoff W, Mehls O. Cystinosis ESGoGHTiCwN: Long-term treatment with growth hormone in short children with nephropathic cystinosis. J Pediatr. 2001;138(6):880-7.

3. Kimonis VE, Troendle J, Rose SR, Yang ML, Markello TC, Gahl WA. Effects of early cysteamine therapy on thyroid function and growth in nephropathic cystinosis. J Clin Endocrinol Metab. 1995;80(11):3257-61.

4. Yang CB, Li AK, Yin YL, Huang RL, Li TJ, Li LL, Liao YP, Deng ZY, Zhang J, Wang B. Effects of dietary supplementation of cysteamine on growth performance, carcass quality, serum hormones and gastric ulcer in finishing pigs. J Sci Food Agric. 2005;85(11):1947-52.

5. Liu G, Wei Y, Wang Z, Wu D, Zhou A. Effects of dietary supplementation with cysteamine on growth hormone receptor and insulin-like growth factor system in finishing pigs. J Agric Food Chem. 2008;56(13):5422-7.

6. Dunshea F. Porcine somatotropin and cysteamine hydrochloride improve growth performance and reduce back fat in finisher gilts. Aust J Exp Agric. 2007:47(7):796-800.

7. Kirkegaard P, Poulsen SS, Loud F, Halse C, Christiansen J. Cysteamineinduced duodenal ulcer and acid secretion in the rat. Scand J Gastroenterol. 1980;15(5):621-4.

8. Pfeiffer D, Pfeiffer C, Szabo S. Development of cysteamine-induced ultrastructural surface changes on duodenal mucosa. Lab Investig. 1987; 56(4):444-50.

9. Selye $\mathrm{H}$, Szabo S. Experimental model for production of perforating duodenal ulcers by cysteamine in the rat. Nature. 1973;244:458-9.

10. Dohil R, Newbury RO, Sellers ZM, Deutsch R, Schneider JA. The evaluation and treatment of gastrointestinal disease in children with cystinosis receiving cysteamine. J Pediatr. 2003;143(2):224-30.

11. Wenner WJ, Murphy JL. The effects of cysteamine on the upper gastrointestinal tract of children with cystinosis. Pediatr Nephrol. 1997;11(5):600-3.

12. Bridén S, Flemström G, Kivilaakso E. Cysteamine and propionitrile inhibit the rise of duodenal mucosal alkaline secretion in response to luminal acid in rats. Gastroenterology. 1985:88(1):295-302.

13. Tarcha PJ. Polymers for controlled drug delivery: CRC press; 1990.

14. Dohil R, Fidler M, Barshop BA, Gangoiti J, Deutsch R, Martin M, Schneider JA. Understanding intestinal cysteamine absorption. J Pediatr. 2006;148(6):764-9.

15. Jaqueline Oliveira N, Antonio Gilberto B, de B JÁG, Letícia M, Fabrício Rivelli M, Carina Megumi N. Evaluation of cysteamine associated with different energy patterns in diets for broiler chickens. Rev Bras Zootec. 2012:41(8):1956-60.

16. EMEA. Committee for veterinary medicinal products. Mercaptamine hydrochloride summary report; 1998. p. 1-4.

17. Robert A, Nezamis JE, Lancaster C, Badalamenti JN. Cysteamine-induced duodenal ulcers: a new model to test antiulcer agents. Digestion. 1974; 11(3-4):199-214

18. Poulsen SS, Szabo S. Mucosal surface morphology and histological changes in the duodenum of the rat following administration of cysteamine. $\mathrm{Br} J$ Exp Pathol. 1977;58(1):1-8.

19. Tanaka H, Takeuchi K, Okabe S, Murakami M. Pathogenesis of the earliest epithelial cell damage induced by Mepirizole and Cysteamine in the rat duodenum. Jpn J Pharmacol. 1989;51(4):509-19.

20. Zhou P, Luo Y, Zhang L, Li J, Zhang B, Xing S, Zhu Y, Gao F, Zhou G. Effects of cysteamine supplementation on the intestinal expression of amino acid and peptide transporters and intestinal health in finishing pigs. Anim Sci J. 2017:88(2):314-21.

21. Cheng-Bo Y, Ai-Ke L, Yu-Long Y, Rui-Lin H, Tie-Jun L, Li-Li L, Yi-Ping L, ZeyYan D, Jun Z, Bin W, et al. Effects of dietary supplementation of cysteamine on growth performance, carcass quality, serum hormones and gastric ulcer in finishing pigs. J Sci Food Agric. 2005;85(11):1947-52.
22. Bai M, Liu H, Xu K, Zou B, Yu R, Liu Y, Xing W, Du H, Li Y, Yin Y. Effects of dietary coated cysteamine hydrochloride on pork color in finishing pigs. J Sci Food Agric. 2017;98(5):1743.

23. Utley JF, Phillips TL, Kane L, Wharam MD, Wara WM. Differential radioprotection of Euoxic and hypoxic mouse mammary tumors by a thiophosphate compound. Radiology. 1974;110(1):213-6.

24. Miners JO, Drew R, Birkett DJ. Mechanism of action of paracetamol protective agents in mice in vivo. Biochem Pharmacol. 1984;33(19):2995-3000.

25. Ali BH, Bashir AA. Diamine oxidase activity in the duodenal mucosa of rats with Cysteamine-Induced ulceration. Pharmacology. 1992;44(5):269-72.

26. Manganaro F, Chopra VS, Mydlarski MB, Bernatchez G, Schipper HM. Redox perturbations in cysteamine-stressed astroglia: implications for inclusion formation and gliosis in the aging brain. Free Radic Biol Med. 1995;19(6):823-35.

27. Svensson BE, Lindvall S. Myeloperoxidase-oxidase oxidation of cysteamine. Biochem J. 1988:249(2):521-30

28. Huang B, Xiao D, Tan B, Xiao H, Wang J, Yin J, Duan J, Huang R, Yang C, Yin $Y$. Chitosan oligosaccharide reduces intestinal inflammation that involves calcium-sensing receptor (CaSR) activation in lipopolysaccharide (LPS)challenged piglets. J Agric Food Chem. 2016;64(1):245-52.

29. Bai MM, Liu HN, Xu K, Wen CY, Yu R, Deng JP, Yin YL. Use of coated nano zinc oxide as an additive to improve the zinc excretion and intestinal morphology of growing pigs. J Anim Sci. 2019;97(4):1772-83.

30. Lowry OH, Rosebrough NJ, Farr AL, Randall RJ. Protein measurement with the Folin phenol reagent. J Biol Chem. 1951;193(1):265-75.

31. Labarca C, Paigen K. A simple, rapid, and sensitive DNA assay procedure. Anal Biochem. 1980;102(2):344-52.

32. Munro H, Fleck A. Analysis of tissues and body fluids for nitrogenous constituents. Mamm Protein Metab. 1969:3:423-525.

33. Hou Y, Wang L, Zhang W, Yang Z, Ding B, Zhu H, Liu Y, Qiu Y, Yin Y, Wu G. Protective effects of $\mathrm{N}$-acetylcysteine on intestinal functions of piglets challenged with lipopolysaccharide. Amino Acids. 2012;43(3):1233-42.

34. Hou Y, Wang L, Yi D, Ding B, Yang Z, Li J, Chen X, Qiu Y, Wu G. Nacetylcysteine reduces inflammation in the small intestine by regulating redox, EGF and TLR4 signaling. Amino Acids. 2013;45(3):513-22.

35. Yoshida N, Yoshikawa T, Ando T, Naito Y, Oyamada H, Takemura T, Tanigawa T, Sugino S, Kondo M. Pathogenesis of platelet-activating factorinduced gastric mucosal damage in rats. Scand J Gastroenterol. 1989; 162(Supp 162):210-4.

36. Yin J, Ren W, Duan J, Wu L, Chen S, Li T, Yin Y, Wu G. Dietary arginine supplementation enhances intestinal expression of SLC7A7 and SLC7A1 and ameliorates growth depression in mycotoxin-challenged pigs. Amino Acids. 2014:46(4):883-92.

37. Wu B, Cui H, Peng X, Fang J, Zuo Z, Deng J, Huang J. Dietary nickel chloride induces oxidative stress, apoptosis and alters Bax/BCl-2 and caspase-3 mRNA expression in the cecal tonsil of broilers. Food Chem Toxicol. 2014;63:18-29.

38. Wu B, Guo H, Cui H, Peng X, Fang J, Zuo Z, Deng J, Wang X, Huang J. Pathway underlying small intestine apoptosis by dietary nickel chloride in broiler chickens. Chem Biol Interact. 2016;243:91-106.

\section{Publisher's Note}

Springer Nature remains neutral with regard to jurisdictional claims in published maps and institutional affiliations.

Ready to submit your research? Choose BMC and benefit from:

- fast, convenient online submission

- thorough peer review by experienced researchers in your field

- rapid publication on acceptance

- support for research data, including large and complex data types

- gold Open Access which fosters wider collaboration and increased citations

- maximum visibility for your research: over $100 \mathrm{M}$ website views per year

At $\mathrm{BMC}$, research is always in progress.

Learn more biomedcentral.com/submissions 